\title{
Don't Uncover that Face! Covid-19 Masks and the Niqab: Ironic Transfigurations of the ECtHR's Intercultural Blindness
}

\author{
Mario Ricca ${ }^{1}$ (D)
}

Published online: 30 April 2020

(c) Springer Nature B.V. 2020

\begin{abstract}
This essay, between serious and facetious, addresses an apparently secondary implication of the planetary tragedy produced by Covid-19. It coincides with the 'problem of the veil,' a bone of contention in Islam/West relationships. More specifically, it will address the question of why the pandemic has changed the proxemics of public spaces and the grammar of 'living together.' For some time-and it is not possible to foresee how much - in many countries people cannot go out, or enter any public places, without wearing a sanitary mask. In short, almost all of us, by obligation or by urgent advice from the public authorities of the various countries, will not live the public sphere with our faces uncovered. The alteration of the social context affecting many Western countries will inevitably involve also the 'local' perception of the Islamic veil and-as a matter of equality - the consistency of the prohibition of wearing it. What will thus become of the ban on wearing it in public places established by some countries such as France and asseverated by the ECHR? If everyone can and will have to go around with their faces covered, why should only Islamic women be discriminated against? Will not the change in boundary conditions produced by Covid-19 also induce Western people to re-categorize the meaning of the veil? And will this re-categorization not directly affect the 'fact' of wearing the veil, that is, its empirical perception? And still, will this psycho-semantic change not show how empirical perceptions are cultural constructs rather than 'objective facts,' as such allegedly independent from the observer's point of view? Consequentially, will the plurality of perceptions and cultural meanings related to the gesture of covering one's own face not gain renewed relevance in determining the legitimacy of wearing the veil? The socio-semantic earthquake produced by Covid-19 compels us to rethink this and other issues orbiting around the translation of 'facts' into legal language; furthermore, it highlights the instrumentality of many ideological/partisan and ethnocentric assumptions passed off as objectivity regarding those alleged 'facts.' The essay will attempt to provide an answer to the above questions by proposing a semiotic-legal approach to intercultural conflicts and, indirectly, the pluralism in law.
\end{abstract}

Extended author information available on the last page of the article 
Keywords Islamic veil · Covid-19 $\cdot$ Intercultural $\cdot$ Pluralism $\cdot$ Secularization $\cdot$ Urban spaces

\section{The Urban Space Emptied by the Covid-19 and the Semantic Transfiguring Dance of Bodies and Covered/Uncovered Faces}

Covid-19 changed urban landscapes around the world. Many cities are emptied of their usually crowding people. Even going around without justifiable reason is banned. But that is not all. Like stars in the sidereal spaces, people must distance themselves from others $2 \mathrm{~m}$ (6,4 feet), at least and, above all, they go around with their faces covered. In some places, they cannot avoid wearing masks, so as to make almost unrecognizable their faces. And, in all likelihood, as soon as the availability of masks will be enough in each country, governments will state that people have to wear them when they are in public places until the world will be no longer impacted by threat of Covid-19.

Even the public squares within Western countries will appear soon as Islamic urban spaces crammed only of veiled women. A surreal image? Maybe. Or, rather, only the snapshot of 'an unusual normality.'

It is more than clear the 'normality of so many veiled faces' is engrained only in what the observer - that is, all of us - know about the implicit plot, or the semiotic cloud, underlying the 'visible urban landscape.' This implicit narrative consists of the Covid-19 epidemic phenomenology. In some sense, the image of a square replete of swarming masked individuals is a scene in which the most important agent-character is still absent, at least from the hermeneutic perspective of an observer not cognizant of the epidemic burst. In this regard, it might be interesting to imagine a time traveller coming from the recent past who saw the squares of a Western city. It would be even more intriguing, however, if this imaginary observer was a member partaking the panel of judges which ruled SAS v. France, 2014-III Eur. Ct. H.R. 341 about the Islamic veil (specifically the niqab). ${ }^{2}$

Who does not remember the essential passages of the above decision concerning the legitimacy of the French ban on face covering (April 11, 2011) in respect of the European Convention on Human Rights? The Court did not converge on the violation of women's dignity and equality that the French government (more or less indirectly) attached to wearing the Islamic veil (burqa, niqab, or even hijab); nonetheless it recognized that putting the veil on the face could legitimately be considered by the State as a conduct not attuned with the social requirements for the 'harmonious living together', at least in France. On the other hand, the different treatment

\footnotetext{
1 Some interesting cues as for the changing self-perception of Muslim women wearing the niqab in public spaces of Western cities swarming with masked non-Muslim people during the Covid-19 outbreak can be found at: https://heconversation.com/muslim-women-who-cover-their-faces-find-greater-accep tance-among-coronavirus-masks-nobody-is-giving-me-dirty-looks-136021.

${ }^{2}$ For a recent critical review of European laws on the Islamic veil and their real or apparent rationales, see [9]; see also, for a Muslim woman's perspective the insightful book edited by [6]. A series of essays about the veiling practices throughout the world can be found in [1].
} 
that 'the fact' of wearing the Islamic veil in public spaces is given in other European countries was 'deflated' of legal and political relevance by appealing to the proportionality principle and its culturally-relative signification. This meant, in other words, that in France, a national state deeply 'devoted' to secularization, or rather laïcité, the religious and anthropological-cultural reasons underlying the behavioral attitudes of people could be utterly disregarded. More precisely, such disregard was to be considered as a full-fledged legal and political choice: so much so that it could annihilate, or silence, any possible narrative aiming to make explicit the meaning of a conduct such as, for example, wearing a veil.

The flip side of the above license to being blind to Otherness is, more in general, that secularization/laïcité can be invoked from then onwards as a smoke-screen to dissimulate the creation and the imposition of any ethnocentric 'objectivity' to be passed off as 'universal reality. ${ }^{3}$ In this way, however, the invisible, the implicit and the unsaid lying beneath the inevitably culture-laden surface of things, behaviors and phenomena, is doomed to remain out of sight; and, even worse, the worldly hermeneutics of dominant groups can be officially and legitimately raised to being considered also under law as the mirror of how 'things are.'

According to the above culturally unbalanced and cognitively mystifying approach in Western countries the 'Islamic veil' is lawfully to be considered as nothing but a piece of cloth on women's faces. As such, its only function relevant for the law is to conceal, or make impossible to see and recognize, people's facial features transforming the public spaces in a kind of 'dance among faceless individuals.' The French Government's complaint about such possibility was sounding more or less like this: How is it possible to 'live together' in such a condition?

That said, I would like to ask the reader to imagine, now, that the above time traveller-judge was abruptly transplanted in a square of a Western country today, which was teeming with masked individuals scrupulously attentive to maintain themselves not less than $2 \mathrm{~m}$ away from each of others. Moreover, assume that at first the judge was prevented from speaking with the performers of this surreal scene, as well as accessing the narrative plots underlying the people's conduct. This is my question: How long would it take s/he to conclude, for reasons of coherence, that what s/he was seeing could (or rather should) be legitimately banned-especially if the square s/he was observing was placed in a French city? ... or the judge was a French member of the ECtHR?

I guess that the readers-especially the Western readers-could argue that in the scene outlined above, wearing a mask is justified by health reasons, and that health is an objective and universal value, as such to be necessarily pursued. On the contrary-the Western reader's argument could go on-wearing an Islamic veil is, if anything, a matter of freedom. No Muslim woman would die, or get sick, for the simple fact that she does not wear her niqab-unless someone from her community were to kill her.

Against these last observations, I would like call into play the different approaches to the Covid-19 pandemic that each state, even among the Western ones, assumed to

\footnotetext{
${ }^{3}$ For interesting remarks on this topic, see [36: pp. $\left.131 \mathrm{ff}.\right]$.
} 
tackle its spreading. In particular, the dispute between the advocates of lockdown and the so-called 'herd immunity' is the most striking and relevant as for the above issue. It orbits around nothing less than the primacy human life and its intrinsic value for economic welfare, and vice versa. Such debate, despite the different opinions, casts a tragic umbra on what can be considered as 'objective' or 'universal.' In parallel, a Muslim could object, the women's dignity, their sense of decency, bodily self-consciousness and individual distinctiveness are just as worthy of consideration as their material life. On the other hand, they could argue that no woman ever died from wearing a veil.

But let us come back to our judge. He does not know the narration, the semiotic plot/cloud underlying the scene he is observing: a square full of people covering their faces. What a surprise if he learned that no one could uncover her/his face, that such prohibition is stated by the state law and going around with one's own uncovered face is qualified as a crime!

What a spectacular turn of the fate! One might even wonder-ironically if it were not tragic_-if it was Allah's revenge against the Westerners' haughty cognitive and cultural blindness. Of course, none of this.

As meta-observers of the stage hosting the overall scene, including both the masked people and the time traveller judge, we know that there is a story epitomized by that surreal 'catholic' masquerade. This story could serve as a source of legitimacy for such a scene, eventually, also before a Western court. All of this presupposes, however, that among the Court's implicit assumptions there is even the lawfulness of covering one's own face when this conduct is supported by justified reasons. But were this assumption to be considered correct, one should infer that going around bare-faced could not be taken as an absolute requirement to allow the unfolding of the Western way of 'living together.'

As a result we would have the following options ensuing from such a statement:

(a) Consider the French ban on wearing the veil. The prohibition of covering the face for religious or cultural reasons would discriminate between 'other reasons' and 'religious ones', to the point that religion would seem to assume, at least as for this specific issue, a negative value. However, it would remain to be assessed if such a conclusion could be deemed to be in tune with the minimum requirements of liberal constitutionalism and, especially, religious freedom insofar as it is inextricably linked to the same ideal of secularization and laicité (even the so called laïcité de combat). And besides, it is no coincidence if the ECtHR did not take in account the 'laïcité' argument in legitimizing the French ban.

(b) Discrimination could be excluded if 'religion' were assumed as something incomparable to 'all other possible reasons.' Nonetheless this conceptual seclusion of religion does not match the social and cultural experience. The modernity project and its champions have carried out the attempt to confine religion outside rationality and-because of something similar to a ripple effect-politics, law, public sphere, economy, etc. Despite the self-aggrandizing rhetoric of secularization, the description of this pervasive plan as an absolute success sounds-as it were - rather immodest. Such judgment is due not only to the presence of religion and the denominational activities in contemporary societies, which is 
anything but dwindling, but first of all to the resilience of religion in the ethical and legal categories of the secular languages. Such semantic persistence is not at all a nominalistic relic but rather a consequence of the anthropological significance of religion and the impossibility to dissociate its semantic and pragmatic projections from the cultural vocabulary of secular societies. The modern divide between secular society and religion had great institutional effectiveness, ${ }^{4}$ but it is largely overestimated as regards cultural categories and habits from ethics to law, from aesthetics to even scientific paradigms. The resilience of religious traits is still tremendously unnoticed in the legal categories comprising private law, criminal law, trade law, corporation law, etc.: in short, the areas of law concerning the organization and the unfolding of people's daily life, in respect of which it would be essential begin to talk of a 'legal theology.' In many cases, this resilience is silent, almost overgrown, as it is one with the basic schemas of what we call 'rationality' (or better, the grammars of the different rationalities). ${ }^{5}$ The socio-political consequences of the conceptual and anthropological incompleteness of modern secularization could be dissimulated within the Western societies for many centuries, but they show all their inconsistency and discriminatory effects in contemporary multicultural and multi-religious societies, as happened, and still happens, in colonial and post-colonial contexts. In multicultural societies, the modern attempt to draw a conceptual insulation of religion cannot work as a cognitive presupposition to legitimate a radical differentiation/discrimination of its cultural and experiential projections. Persisting in not acknowledging

\footnotetext{
$4 \ldots$ and this is true even despite Schmitt's contention regarding the theological dissimulated features of modern political categories: see [46].

5 I consider this a crucial point as concerns the investigation of secularization and religion, especially from a transnational perspective and in contemporary multicultural societies. Many scholars have argued, in recent years, that the concept of secularization should be renewed, or at least reconsidered beyond its traditional and legal understanding. Even if with different accentuations, see, in the vast literature: [2, $3,8,13,24,30-32,35,48,49]$. From various perspectives, all of them emphasize the need to focus on the relationships between secularization and religion from a cultural-anthropological point of view so as to make evident the relativeness of any kind of separation among the 'secular' and the 'religious.' The blurring of these domains and the deceptive politics of state neutrality are explored against the foil of the problems raised by post-colonialism and multicultural societies. Nonetheless, all these contributions address secularization from political, sociological, philosophical and anthropological approaches, but exclude the legal one. In some cases, they even put at odds the cultural/anthropological understanding of religion and the traditional legal declination of secularism as state/religion separation. I think that when these authors refers to the legal aspects of secularism, they actually focus their attention on public and constitutional law, and more specifically the issues orbiting around religious freedom and the distinction among forum externum and forum internum so relevant for the 'exteriority' of modern legal approach. They do not take in account in any way all the constellation of legal concepts inherent in private law, criminal law, trade law, family law, etc. In so doing, they lose sight of the huge cultural resilience of religion there is in the legal vocabulary of Western secularization, which still pervades quotidian life not only in the West, but also in the post-colonial countries, not to mention contemporary China and Japan. But this theoretical and empirical 'strabismus' prevents them from pursuing their own goal of analyzing the cultural aspects of secularization and, most importantly, the huge role of private, criminal etc. legal categories in the phenomenology of cultural life in all societies. I think that all their criticism about the camouflaged and disguised cultural signification of religion will remain in danger of not leading to any relevant outcome until they are accompanied by interdisciplinary endeavors to make law, in all countries, responsive to cultural difference.
} 
the inadequacy of the Western 'secularization project' to achieve such effect equals 'not understanding' what religion is from an anthropological point of view and the cultural significance it has, and has played, throughout history of human societies.

(c) Another option could be imagined as coextensive with the following argument: face covering would remain banned, as a general rule, but public health reasons, and only these, could support a legitimate derogation from that rule. The assessment beneath this derogation or counter-rule, however, would raise the question of why public health should be considered more valuable than other religious or cultural ones. A possible answer gauged precisely on the behavioral requirements inherent in the Western way of 'living together' could be, in all likelihood, as follows: public health concerns are higher than others because in some cases, like outbreaks, people required by law not to cover their faces in the name of the 'Western way of living together' would obey, on the contrary, the imperative of 'dying together,' and each because of the other. Insofar as life is the pre-condition that makes viable the enjoyment of all other rights, its protection legitimates an exclusive derogation of any rule, as in the case of self-defense, and thereby even the prohibition to cover one's own face in public spaces. From this point of view, it could also be argued that no one actually ever died for not having covered her/his face... except for some particular situations in which the face covering is a by-product of the necessity to adopt specific measures and/or tools for health protection. The Islamic veil is ordered to protect neither life, nor health, consequentially it cannot be considered as a valid source/motivation to legitimate derogation to the behavioral standard inherent in the (Western) living together.

And so far, the above argument would seems to run smoothly and without noticeable inconsistencies, except that the same conduct/gesture, covering one's own face, simultaneously turns out to be an obstacle against 'living together in public spaces' and an essential tool 'to live together in public spaces'. Needless to say, the immediate objection to this dichotomous signification of the 'face covering' would be that what matters about its legitimacy is not the behavior in and of itself, namely taken in its morphological appearances or formal features, but rather its contextual meaning and the related teleological function.

Should the last argument be correct, however, its implication would be that what is to be taken in account when assessing the legitimacy of a specific behavior is not its 'objectified/reified morphology' as rather the semiotic cloud/landscape underlying it: and therefore, the relational web comprising both its experiential context and teleological significance. Subsequently, to compare the different semiotic webs beneath the different behavioral patterns at stake, the related contexts and ends should be translated one into another so as to develop a common semantic and axiological ground to be used in their cross-assessment. To put this discourse in concrete terms, the comparison between the Western standard of 'living together with bare faces' and the 'wearing of the veil' should undergo a crossing appraisal/examination relying on the semiotic (contextual and teleological) webs underlying each of them. Such a survey, as such preliminary to any empirical and axiological judgment, 
should include an anthropological excursion in the landscapes of sense and experience included in both Western and Islamic imaginaries so as to establish what can be semantically and teleologically considered as analogous, paralleled, reconcilable; or instead incommensurable, divergent and radically incongruous. I would not be so sure that such a semiotic fathoming would leave the morphological opposition between bare face and veiled face in its place.

The significance of the veil in Islamic culture includes more than only the "visible and visual' discrimination of Muslim women and is also experienced by them in different ways. ${ }^{6}$ The wearing of the veil has also to do with the relevance to be given to the voice rather than exterior appearances, the inner beauty rather than the outer one, the spirit rather than the matter, the ethical dimension rather than the sensuous one, etc. ${ }^{7}$ These psycho-cognitive patterns have consequences, in turn, on the way to conceive and make public spaces, as well as the relationships that take shape inside, and cumulatively shape, them. As regards, then, the women's sense of selfdistinctiveness and dignity, the semio-ethic universe orbiting around the 'wearing of the veil' contributes to molding their conception of 'property', the dislocation across public and private spaces of their personal value, the sense of respect for their privacy, etc.

Were the ECtHR judges cognizant of all these implications of the veil when they ruled $S A S$ v. France, 2014-III Eur. Ct. H.R. 341? And were they sure that the semiotic universe surrounding the veil and its components would be semantically irrelevant with respect to the values enshrined in the human rights catalogue? And that the image and the practices of public spaces ensuing from those patterns of subjectivity could not be translated into, and transacted with, the Western image of public spaces? Maybe, by using as translational/metaphorical interfaces the same principles and values invoked as axes of the Western ideas about public space and 'living together?' On another side, can the Western observers assert without any doubt that the values underlying the 'wearing of the veil' are completely unsuitable, or in contrast, with regard to the possibility of organizing a reasonable public space for living together-however distant this public sphere may morphologically appear from the Western one?

In the same vein, it could be argued (x) that the veil is only the gateway to an entire and multifaceted universe of sense and experience; and, most importantly, (y) that the assessment concerning the legitimacy of the veil, as well as any object or conduct from other cultures, should be carried out through the translation/transaction between the semiotic frameworks (or semantic networks) underlying the meaning of that object or conduct in both the cultural universes in comparison. Without such a semiotic openness connoting the hermeneutic gaze of the interpreter/judge there is no room left to provide any kind of justification to the different and/or contrasting claims at stake. The consequence will be that the principle/values included in the enunciations of the human and/or fundamental rights, and invoked by each

\footnotetext{
${ }^{6}$ On discrimination and the politics of visibility and invisibility, also as regards the Western ethnocentric semanticization of the Islamic veil, see [37].

7 See [19].
} 
part in order to support its own claims, will be doomed to fall prey to the instrumentalization and the antagonistic exploitation of their semantic vagueness. Biases, ethnocentrism, semantic and anthropological blindness, reification and discrimination will become, under these conditions, the prominent features of any assessment. The final result will be, inevitably, the outcome of a single-minded struggle for public space, in many cases silently or surreptitiously oriented to neutralize the Other's presence from it, rather than to construe an inclusive horizon to live together. The authentic and effective reasons underlying the final assessment/judgment will remain, in this way, invisible and to some extent even camouflaged under the dazzling appearance of the alleged and culturally construed self-evident thinghood of the object or the conduct constituting the bone of contention. In some situations, however, such underlying reasons and the semiotic webs coextensive with them are-as it were-urged to surface, so that the presumptive semantic self-evidence of the previously assessed object or conduct comes out utterly destabilized. This situation, as in the case of face covering, is what can be illustrated through another scenario involving again our time-travelling ECtHR judge.

\section{Veils, Masks and the Betrayal of Grotius' Inclusive Secularization}

At this point, I would like to ask the reader to imagine an alternative scenario in which the time-traveller judge, when facing the square crowded of individuals with their faces covered, suddenly comes to learn that to move through public spaces with the face uncovered is (now) banned; and that such prohibition is ordered to protect people's health and, in sequence, their dignity, freedom and psycho-physical integrity. As long as individuals are in public spaces, they will be subjected to the legal rule to not uncover their faces-also in reality, however, this measure is about to become a general legal standard in many countries: at least, until an effective cure or a vaccine against the Coronavirus is discovered. Of course, after the initial surprise, our imaginary judge will be prone, in all likelihood, to ask what kind of disease can be dangerous enough to require a legal measure so tough that it must be respected while impinging so heavily on the normal 'living together' style. Moreover, we can concede that the judge finally learns of the Covid-19 planetary outbreak. It is fair to assume that despite her/his having partaken in the decision SAS v. France, 2014-III Eur. Ct. H.R. 341, he cannot help but share the legal provision regarding the ban to uncover one's own face in public spaces. At that point, however, a new issue, anything but abstract, might arise. What if someone wore the mask also for religious reasons? Or she adjusted a mask so as to make it as similar as possible to an Islamic veil? Or a veil as similar as possible, even in its health care functions, to a mask? Could we reasonably suppose that a secular state, such as France, might legitimately derogate from such a public health measure as regards Muslim women, if this exception was designed just to avert the public use or display of religious symbols? Or, alternatively, that a state might prohibit the wearing of a veil appropriately adjusted for health protection, only because of its additional/complementary religious meaning? The odds are, probably not. 
How could a state or a judge simultaneously impose and prohibit the same behavior, gesture or object?

Such a paradox would unmask not only the prejudice but also the anti-Enlightenment myopia shown by the ECtHR judges against the claims of Islamic women in giving their decision in SAS v. France, 2014-III Eur. Ct. H.R. 341, and other similar subsequent statements. ${ }^{8}$ As noted above, covering one's own face, as well as wearing a veil, can include many significations collateral to the religious one. As such, these additional meanings should be considered with respect to their legal relevance and the possibility of being worth of legal protection, maybe also in derogation from the previous standard of living together. More in general, then, speciously defining as religious what, in its morphological appearances, can play also other "common significations', and this only for nominalistic or ideological motivations, would seem to be not only blatantly discriminatory but also resoundingly in contrast with any Grotius-inspired, and thus Enlightenment-inspired rationality.

Grotius' legal and political lesson was essentially to divest of religious signification and relevance everything that could be considered as something also, or alternatively, something expressing even rational or secular meanings. ${ }^{9}$ As is well known, this rhetorical recipe was ordered to neutralize the social conflict triggered by the struggle for the religious legitimation of political power and triggered by the antagonistic pluralism of Christian denominations. Nonetheless, Grotius' secularizing formula, which was centered on what would be true, or valid, even if God did not exist (the well-known 'etsiamsi daremus'), comprised a kind of re-semanticization of social experience and the legal language. Apparently, Grotius founded the determination of his common legal theology on the rational evidence of many of law's categories and their morphological evidence. In simple terms, it is as he quipped, speaking to the representatives of the various denominations in conflict: "Well, are the categories of contract, theft, obligation, fraud, etc. perhaps different for you Catholics, Calvinists, Lutherans, or Anglicans, etc.? If not, as from a rational point of view it is so, then those categories can be considered true and valid for all of you and by relying on them, all of you can construe the social architecture within which people of different faiths can peacefully coexist in the future.'

In fact, the denominational perspectives on contract law, obligations, family law, and property law, were not amenable to being entirely overlapped. Nonetheless Grotius was in a relatively comfortable position to engender implicit intercultural metaphors, even if rather rough, by referring to the morphological appearances/features of these categories just because he could rely on a cultural and moral-legal

\footnotetext{
${ }^{8}$ In a huge literature, a recent critical overview on veil ban in the ECtHR decisions can be found in [28]. See, however, the different opinion expressed on this topic by the UN Human Rights Committee. See, in this regard, https://www.ejiltalk.org/the-un-human-rights-committee-disagrees-with-the-european-court -of-human-rights-again-the-right-to-manifest-religion-by-wearing-a-burqa/. See also Dakir v. Belgium, App. No. 4619/12 (Eur. Ct. H.R. July 11, 2017); Belcacemi and Oussar v. Belgium, App. No. 37798/13 (Eur. Ct. H.R. July 11, 2017). And, even if with specific regard to hijab in workplaces, Court of Justice of the European Union-No 30/17Luxembourg, 14 March 2017.

${ }^{9}$ On Hugo Grotius, in the most recent literature, see, at least, [7, 17, 20, 29, 33, 50]. As for the edition of De jure belli ac pacis, see [23].
} 
background inherited from Medieval tradition and the theological-legal apparatuses elaborated by the Second Scholasticism. ${ }^{10}$ Grotius' shaping of the conceptual figurations related to the alleged natural-rational features of contracts, obligations, crimes, etc. was, actually, the result of a silent metaphorical work; or, in any case, it produced metaphorical outcomes. Hence it was generative and not only declaratory. At the same time, the conceptual legal standards so drawn and carved from Roman-Medieval tradition were capable of performing their social functionality only because they rested on a relatively homogeneous common background. Although almost four centuries have passed since Grotius' De jure belli ac pacis, such relative cultural homogeneity lurks even today beneath the lexicon of European legal experience beyond the differences between common law and civil law. ${ }^{11}$ It can still be perceived, despite the latent cultural discordance, or even the prejudices, extant between the people with a Protestant bildung and those traditionally Catholic, that is, between Northern and Southern Europe. ${ }^{12}$ In all likelihood, it does not seem inappropriate to ask if these differences, when not even divergences, are not rooted in cultural discrepancies originating in the rough metaphorization, passed off as nothing but the discovery of pre-existent universal essences, which accompanied and, in some sense, underpinned the modern secularization and jusrational/natural law doctrine.

The story of the dissimulated and rough metaphorizations underlying the legal discourse of modern secularization, and the problems still today arising from them, give us a crucial warning stemming from the past. That story and its long-term consequences tell us how important it is, today, to avert any intercultural translation unable to go beyond the morphological appearances of conducts, things and phenomena when each of us is facing the effects of contemporary multicultural globalization.

The paradoxical coincidence of the mask and the veil, taken in their respective material morphology, is nothing but the ironic requital of a lack of metaphorization in interpreting and translating what the Islamic veil is beyond its morphological appearances and nominal religious ascriptions. The current almost whimsical overlapping between masks and veils actually 'unveils' the intercultural and cognitive flaws of a non-metaphorical translation. Even worse, it entails a real misunderstanding of the genuine kernel of Grotius' cultural strategy of rationalization/universalization and, consequently, the betrayal of its inclusive original inspiration. Covid-19, among many other effects, ruthlessly unmasks the complete failure to understand the original logic of modern secularization, as well as its historical-cultural significance, on the part of both French law-makers and, thereby, the ECtHR judges.

The criticism made by the Adorno and Horkheimer, in their Dialectic of Enlightement, perfectly applies to the emphasizing of the morphological

\footnotetext{
10 See [50: pp. $316 \mathrm{ff}$.$] .$

11 In a boundless bibliography, with specific regard to Grotius' influence on both civil and common law, see [22]; but see also the contributions included in [33].

12 Some evidence of these discrepancies, or inhomogeneities, could be traced, for example, in disparate areas of contemporary civil law such as family law and inheritance law with regard to the agreements for the future succession, contract law with regard to the ban on pactum commissorium, and processual law as for the reverted burden of proof.
} 
appearances/features that undergirds the veil ban and its judicial legitimation. ${ }^{13} \mathrm{Nev-}$ ertheless I would argue that such criticism should be gauged not as much against Enlightenment and the modern rationalizing endeavors as rather averse to the ontologization of their products. What remains still unnoticed in the process of rationalization and-in Cartesian terms-clarification of ideas that substantiate the modern path towards Enlightenment is its crucially creative signification and processive gist. 'Enlightenment' conjures up not a fact or, a state of things, but instead a periphrastic disposition imbuing the intertwining of the human mind and the environment, namely human experience. 'Enlightenment' is not a reified condition, nor an ontological arrival point, as rather the action of 'illuminating' and 'being illuminated.' ${ }^{14}$ Nothing is better suited to express such disposition than the process of metaphorization. But, as observed above, it is the same process at work behind Grotius' proposal and rhetorical strategy encapsulated in his proposal for culling the "morphological appearances' of legal categories shared by people of different faiths as the ground on which to build a peaceful coexistence among differences. The (relative) success of Grotius' project in neutralizing the denominational-political conflicts of early modernity is entirely due - in my view-to the re-semanticization/metaphorization that it silently entails. Symmetrically, its conceptual flaws, incompleteness, and dis-functionalities, which the contemporary world is still atoning for, depend on the misunderstanding of its metaphorical nub and the subsequent leaning toward the reification of experience and the related categorizations (that is, the Dialectic of Enlightenment). Still, Grotius taught, at least to Westerners, that if what is apparently belonging or ascribed to the religious domain is also endowed with other profiles of 'commonsense significance', the features supporting these alternative categorizations are to be focused and exploited in order to construe a semantic social contract, namely a lexicon, for peaceful coexistence amidst and through differences. ${ }^{15}$

The main unanswered issue in Grotius' socio-semantic strategy is, rather, how to decide what feature of experience (namely: of things, actions, events), in order to determine a 'commonsense signification,' is to be focused on and picked out. In this regard, and differently from the method adopted by Grotius, it should be emphasized that the 'common' does not coincide with some already shaped morphological appearance of things. If it does, the entire operation would be in danger of falling prey to ethnocentrism and the silencing of 'implicitness', that is, the semiotic

\footnotetext{
13 See [26].

14 It could be very useful-I would like to suggest - to reconsider the relationships between secularization and multiculturalism in the light of Blumenberg's [4] approach to Enlightenment and anti-ontologizing theory of 'un-conceptuality' [5]. On the other hand, I believe that the better explanation of the modern and contemporary leaning toward a self-reflexive seclusion of the human symbolic universe from the world's global semiotics can be found in Kafka's tale titled 'The Silence of the Sirens'. On the parallelism between Kafka's tale and Horkheimer and Adorno's Dialectic of Enlightenment see the interesting insights proffered by [34]. Kafka's warning, however, is already included in Homer's 'original' Odyssey especially with regard to the story of the Phaiacians' petrified ship and Tiresias' prophecy. For an anthropological-semiotic reading of Odyssey, as an immense encyclopedia on hospitality, to be intended as an explanation of the relationship between the Self and the Other, the mind and the environment, and finally word and experience, I refer to [44].

15 This semantic strategy applies even more easily to the hijab than to the niqab, or the burqa.
} 
network underlying any categorization molded according to a specific cultural perspective. ${ }^{16}$ For example, if the 'common feature' of the veil were considered only for its 'being materially' a piece of cloth put on the face, almost inevitably the reasons and the normative-axiological axes invoked in order to legitimate the different views about wearing it, or not, will be declined in polarized/antagonistic terms. But this approach would preclude, in and of itself, any chance of conducting an intercultural/ metaphorical translation. As usual, one part of the controversy would claim for the right to wear that piece of cloth for some reason, while the other one would try to delegitimize the 'fact' involved in that claim for other reasons. In legal terms, this means that the constitutional values/principle, or the human rights enunciations, will be involved and exploited for the purpose of the dispute only as instrumental and rhetorical weapons, but without any genuine commitment to carry out an intercultural understanding and translation. Each part would try to cling onto one or another of them (and the related semantic spectrum) taking the focused principle/value as an axis for the hierarchical legitimation of her/his own claims but lacking any concern for the possibility, if not the need, to give room to some 'meaning transactions' concerning her/his own assumptions. In doing so, each part would try to take advantage of the semantic vagueness of constitutional and/or human rights enunciations in order to articulate claims bereft of justifications that are self-reflexively situated and responsive from a semiotic-intercultural perspective. The overall result would be that the ensuing conflict between the values/principles called into play by each part and the related balancing test entrusted to the judge would be carried out on the basis of reified worldviews: as such completely caged within the apparent contrasts between the morphological appearances of the objects or the behaviors, and dramatically cut off from any semantic translation/transaction between the semiotic networks underlying their apparent features (according to each of the different cultures at play).

In this vein, although Western (from a Christian cultural tradition) and Islamic people find in the 'same' veil, from their respective point of views, different things, each part presumes (but also pretends) that it is the same 'object' with the 'same objective signification.' All the contrast, however, is nothing but a rhetorical mummery. The surreptitiously assumed and self-centred objectivity claimed by each part is merely the outcome of a merely simulated overlapping between the conflicting and untranslated semiotic landscapes inherent in the different views at play. The apparently common bone of contention precariously floats, instead, on a minimum common existential support that is only the defective material remnant of a dodged, or aborted, translation of those semiotic clouds. And yet, this 'minimum' is anything but an icon of universality. Rather it will only serve as a rough basis for the rhetorically orchestrated struggle between social and semantic universes destined to remain deaf to one another and 'refractory' to the reciprocal translation of their own semioexperiential networks. Once again, that morphological minimum will be quite the opposite of the 'universal ground' on which differences might converge. It will be,

\footnotetext{
16 An interesting comparative examination of how secularism and its political/ideological use has been surrounding the 'veil issue' in France and Turkey can be found in [21].
} 
instead, only a semantic battlefield doomed to be unknown for its possible semantic and intercultural projections.

In concluding these critical remarks on the assumption of morphological appearances as a medium for intercultural translation, I would like to underline that the equivalence between the mask and the veil—at least, in my view-has nothing to do with their material similarity. In this regard, for example, a far more apt term of equivalence in translating the significance of the veil into the Western semantic horizon would be everything in this culture that plays the psycho-social role of a symbol of decency. The Islamic veil has a lot of possible semantic declinations inside the Islamic culture, but certainly its psycho-aesthetic function in women's self-perception cannot be excluded. Although it may appear a bit provocative-but without a shadow of disregard for the cultural and religious implications tethered to the icon-veil-I would suggest considering the equivalence between the wearing of the veil and the habit of wearing underwear. Who could deny that many Western women would feel deeply uncomfortable going around without underwear? Imagine, in this regard, that at a non-Western airport a Western woman was requested to slip off the underwear she wears under her clothes, exactly as Islamic women are currently requested, in International airports, to strip off their veils. I am sure that that the average Western woman would feel insulted by having to comply with such a request. Unfortunately, I am almost sure that to date no average Western woman would realize that what she would feel if forced to put off her underwear for airport security is somehow analogous to what an Islamic woman experiences when she is actually ordered to remove her veil. Just to be clear, in proposing this example I do not want to in any way underestimate, or overshadow, the veil's religious significance for Muslims and the identitarian meanings it assumes in contemporary times, especially within non-Islamic social contexts. ${ }^{17}$ Quite the opposite, and symmetrically, I want to stress that it is important not to allow the religious features to cast an umbra on all the other semantic and pragmatic profile related to the veil-which should apply, on the other hand, to all the possible items from any cultural universe. To silence, under the 'denotative veil' of religion and in the name of secularism, all the other meanings and semiotic ramifications stemming from the veil is, on the contrary, to underestimate their axiological and legal relevance. Such an approachit needs to be reiterated-equals a literal inversion of Grotius' logic of cultural/legal rationalization, which ends up turning upside down the secularization (metaphorical) strategy through which he gave momentum to the overall subsequent modern legal experience.

The above unusual example points out only one possible semantic intercultural channel to translate the manifold meanings of the veil. An endless series of other metaphorical correspondences could be found. What is most important, rather, is that it shows how metaphorical transposition (a kind of intercultural transduction) is crucial to grasping the semiotic clouds underlying the morphological appearances of 'things' and 'behaviors' as molded by each culture and conveys their reciprocal translation.

${ }^{17}$ See, in this regard, $[14,15]$, and some of the essays in [6]. 


\section{The West Against the West: The Farcical Discriminating Interpretations of Face Covering Among Europeans from Different Experiences/Cultures during the Covid-19 Outbreak}

The worldwide spread of the recent Covid-19 outbreak provides an opportunity to test the discriminatory implications that face covering may assume even in the relationship between Western people from different cultures and geographical areas.

As everyone knows, at least in Europe, Covid-19 exploded first in China and then in Italy. The effects of the outbreak spreading reached England with a delay of more or less two weeks. In this time frame, the UK Prime Minister, Boris Johnson, launched the so-called 'herd immunity' strategy. Unlike Italy (China and other countries), the United Kingdom would not be adopting any restriction on the free flow of people, productive and commercial activities, transport and so on. UK citizens, in short, could and should continue their life as always. Whoever was doomed to die... they would die, despite all the sorrow and mournfulness that the loss of many loved persons would cause.

At first, the British willingly followed their Prime Minister's directives, at least on average. Meanwhile, the few dissidents were more and more frightened. Among these, there were many Italians living in the UK, but, many as migrants, actually living in a kind of cultural/communicative inter-space lying across the national territorial frames and borders. The result of this multi-sited life experience was the engendering of a semio-space continuum by virtue of which Italian people filled the UK public and private places adopting the health measures corresponding to the lockdown strategy already ordered by the Italian authorities. The more the UK Prime Minister's call for 'normality' echoed in the media, the more they felt motivated to act according to the Italian-mandated health measures and fill the UK urban spaces with their extra-territorial personal conducts. ${ }^{18}$ Among these behaviors there was the

\footnotetext{
18 An explanatory clue about the inter-space semiotic continuum constituting the Italian immigrants environmental experience illustrated above can be found in Dewey's following icastic words: "The words 'environment,' 'medium' denote something more than surroundings which encompass an individual. They denote the specific continuity of the surroundings with his own active tendencies. An inanimate being is, of course, continuous with its surroundings; but the environing circumstances do not, save metaphorically, constitute an environment. For the inorganic being is not concerned in the influences which affect it. On the other hand, some things which are remote in space and time from a living creature, especially a human creature, may form his environment even more truly than some of the things close to him. The things with which a man varies are his genuine environment. Thus the activities of the astronomer vary with the stars at which he gazes or about which he calculates. Of his immediate surroundings, his telescope is most intimately his environment. The environment of an antiquarian, as an antiquarian, consists of the remote epoch of human life with which he is concerned, and the relics, inscriptions, etc., by which he establishes connections with that period.

In brief, the environment consists of those conditions that promote or hinder, stimulate or inhibit, the characteristic activities of a living being. Water is the environment of a fish because it is necessary to the fish's activities - to its life. The North Pole is a significant element in the environment of an arctic explorer, whether he succeeds in reaching it or not, because it defines his activities, makes them what they distinctively are. Just because life signifies not bare passive existence (supposing there is such a thing), but a way of acting, environment or medium signifies what enters into this activity as a sustaining or frustrating condition.': [10: p. 13]. For an enactivist perspective on the relationships between mind, body, language and environment, which is very close to Dewey's approach, see [11, 12].
} 
use of sanitary masks. The result was that they were moving through the crowd, public vehicles and workplaces with their faces covered by the masks and distancing themselves, as far as possible, from the unmasked others.

According to the press and media reports, a general mocking attitude suffused the relationships between Italians living in the their sanitary-ethnic inter-space and the majority of UK citizens. The autochthonous people did not understand those people wearing the mask, so worried about being too close to others, etc. Although all UK citizens were well informed about the burst of the outbreak in China and Italy, it was as if they believed in a kind of magic/ethnic/territorial immunity. They were cognizant of why those people were wearing the masks and assuming the self-distancing behaviors, at the same time, however, they were thinking and behaving as if there were no pandemic, or pretending to believe the 'herd immunity' strategy, maybe, as 'Covid-exempted agents.' Italians were considered too dramatic and theatrical-as usual. This suspicious and mocking attitude reached its climax, becoming discriminatory, when Dr. Christian Jessen, a TV star in England, on FUBAR Radio said about the outbreak in Italy and the related lockdown: "This might be a little bit racist to say this, [and] you'll have to make apologies, but do you not think it's a bit of an excuse? The Italians, any old excuse to, you know, shut down everything and stop work for a bit and have a long siesta." 19

However, the tragic way the situation developed compelled the UK Prime Minister to give up the 'herd immunity' strategy and, progressively, declare a state of emergency requiring a complete lockdown... just as in Italy. The final twist of Johnson's revirement was his own contagion from Coronavirus and, in the end, his intensive care admission. Before this change of direction in facing Covid-19, however, the ethnic-spatial diffractions drawn by, and arising from, Italians' conduct were even going to assume the traits of a serious legal struggle. For example, many Italian mothers, following the health measures adopted in Italy, decided that their children would not go to school so as to avoid any contamination. Nonetheless, those mothers were deeply worried that such a choice could trigger the intervention of Social Services and the imposition of sanctions, potentially even risking the custody of their own children.

It sounds really strange to have to say that 'fortunately' the cultural-space diffractions engendered by the inter-spatial, or Anglo-Italian, lived dimension of those mothers transmuted in a cultural/spatial/political continuum. At some point, the semiotic landscape underlying Italian mothers' conduct transplanted in both the territories and the minds of UK citizens.

What is salient in this story is that the mask, namely the same object with the same morphological features, has become a means of differentiation and discrimination. In some sense, its different interpretations transformed it into a frontier, a border, able to engender conflicting (lived) spaces. From a legal point of view, the overall issue took shape because some elements constituting each of the cultural/ spatial circuits at stake were-at least, potentially_relevant for the other one and

19 See at https://www.independent.co.uk/news/world/europe/coronavirus-dr-christian-jessen-italy-outbr eak-embarrassing-bodies-siesta-a9399071.html\#Echobox=1584094956. 
its values/principles. What made the difference was precisely the British's cognitive refusal to consider the semiotic clouds beneath the same 'object' as lived in the Italians' culture and trans-territorial environment. Something analogous can be said for the Italian mothers' choice not to send their children to school. From a cultural/legal perspective-that is, the British one until the burst of the outbreak even in Upper London - this choice was an unlawful behavior insofar as it would compromise the best interests of their children. From the opposite perspective, the Italian migrants' one, it was a means to protect children's health, as such to be considered to prevail over the right to education. The only problem with this-otherwise legitimate-plurality of views was that the 'march' of Covid-19 throughout the world revealed how much the UK Government's approach had been groundless, as a matter of 'fact,' even before the impossibility to contain the unbearable spread of the epidemic became undeniable. In other words, in the UK the outbreak's spread was already underway when Johnson still was speaking about the 'herd immunity.' With respect to this empirical datum, the conduct of Italian migrant mothers, though linked to the Italian cultural-spatial framework, had been utterly congruous and lawful. Consequentially, if British Social Services, during the time lag between the Covid-19's explosion respectively in Italy and England, had taken the children away from their Italian mothers, today they might have to face, in all likelihood, a number of claims for damages. And besides, the UK Government's action retrospectively appears, on balance, inconsistent with the same UK legal system because of its erroneous - and obstinately erroneous-assessments of the true scale of the pandemic. At some point, however, the political bent turned into a psycho-cognitive reluctance to translate the Italian migrants' behaviors and the underlying space-semiotic networks so as to achieve a semantic/spatial neutralization of their cultural difference.

Surely any British citizen would have been able to understand, for example, the Italian migrant mothers' motivations. Nonetheless, they were willingly withdrawing from doing so. But this attitude was nothing but a refusal to translate and transact. Doubtless Covid-19 and the related health measures were categorized in different ways by UK Government and the majority of British people, on one side, and the Italian Government and the Italian migrants, on the other one. However-and this is the point - to what extent can the law, and specifically the national legal systems, be deemed immune from any kind of Otherness and endowed with the power to be blind to different semantic-spatial circuits? How far can the legal systems' alleged self-referentiality unmoor from the at least potential relevance, with regard to their axes of legitimacy, of the concurrent semio-space dimensions; or simply those different for those experiential 'spatialities' which law presumes as extant, or is trying to plan and mold? If we take in account the UK experience with Covid-19, does that pretention at self-referentiality not appear completely collapsed in on itself, at least insofar as it refers not only to the deontic profiles of legal enunciations but also to the empirical facts and the related cognitive schemas? To put it more simply: which semantic-spatial framework was actually relevant for UK law? That assumed, at first, by the UK Prime Minister? Or instead the other one implicitly drawn by the Italian migrant mothers and assumed as a representational compass to guide their conduct? 
In any case, it would be a mistake to think that the crux of the matter has been determined, and somehow decided, by the evidence of the facts. Facts and events do not mean anything in and of themselves; nor do they speak for themselves. The evolution of the outbreak in the UK led to the lockdown because those facts have been assessed in accordance to the basic values and principle of the UK legal system. But such values and principles were extant even before the lockdown. With respect to these values the Italian mothers' behaviors, the semio-spatial environment they engendered and the related underlying semiotic networks were already worthy of protection and endowed with their legal relevance. What changed the political line of the UK Government was essentially the assumption of a different axiological option and a different approach to the translation into the legal language of what was to be considered as 'fact.' By and large, it is precisely for this reason that making oneself cognitively deaf to Others' cultural reading of facts always puts one in danger of passing off one's own culture-laden interpretations of facts as the reality in itself, as something portraying things as they are. ${ }^{20}$ Experience shows, however, that such a hermeneutic attitude turns, too many times, into a source of blind discriminations. It proves to produce the same outcome, on the other hand, also when tested for compliance with the values that undergird the same cultural framework and legal systems from which, in turn, its interpretive assumption allegedly gush up-as the UK experience with Covid-19 and Italian ruthlessly shows.

It should be observed that Western culture, and specifically the ECtHR, did nothing different as concerns the Islamic veil. The integral reluctance to take in account the semiotic networks beneath the 'wearing of the veil' and their semantic ramifications 'made' the facts and the 'categorizations of facts' cognitively unbalanced, transforming the veil and its meanings in a cultural barrier and, in the end, in an antagonistic symbolic barricade. In this way, what should not have been separated at the level of cognition and experience was instead disjoined by a decision of authority.

In the same vein, many children, women and men of Italian origin lived in the $\mathrm{UK}$, for 2 weeks, in a precarious intercultural space. A precariousness that was the consequence of a withdrawing from any intercultural translation, and therefore the result of implicit intercultural processes, lacking any reflectiveness and consisting mostly of a reaction to Otherness rather than arising from a thoughtful commitment to translation and cognitive transaction.

At the time of writing this essay, ${ }^{21}$ the semantic-spatial discrepancy appears to have been dissolved, but this is not exactly the whole truth. If any Italian individuals forced to work in the UK without protection equipment died, this means that the time lost in taking prompt health measures has left a mournful trail in its wake. It is a gap hurting also the huge number of UK citizens who have died of Covid-19. It cannot be excluded that someone will ask for justice for many of those deaths now that the Italian migrants' semio-spatial dimension has been recognized as continuous, if not even coextensive with the UK one.

\footnotetext{
20 In this regard, see, for an anthropological approach [25, 27].

21 April 24, 2020.
} 
On the other hand, the above continuity/coextensiveness constitutes the basic lesson to be learned from Covid-19. While we, the humans, were indulging in thinking about ourselves as ontological entities divided by geographical frontiers and ideas, national borders and polarized cultural schemas, the Coronavirus was transplanting and traducing itself from one body to another, on a planetary scale. The global semiotics coextensive with its inter-corporeal transitions allowed for it to almost simultaneously dwell in our bodies despite their different nationalities and geographical locations. ${ }^{22}$ While our minds were feeling still tightly separated from one another, each potentially exempt from any need to translate Otherness and figure out the Other than Self as an Other of and with Self, conversely our bodies were reciprocally contaminating so as to transform the epidemic space in a worldwide continuum. ${ }^{23}$

But Coronavirus - as stressed above - is transmitted by human bodies and their behaviors. Therefore the deaths that occurred and will continue to happen should be considered essentially as the result of a semiotic diffraction and a subsequent lack of cognitive attunement between the existential, dynamic space of the virus and the cultural spaces and geographies within which the different groups, nations, ethnicities, etc. believe they can live (relatively) secluded from on another as selfreferential entities. If this is correct, any 'ought-to-be system'-including any legal

\footnotetext{
22 For some considerations from a Spinozist-Deleuzian perspective about the Covid-19 outbreak and the bodily/spatial continuity of humankind see [40].

23 The referral to Global Semiotics is intended to evoke Sebeok's seminal work Global Semiotics [47]. What Covid-19 brought to the fore is the inextricable relationship between the semiotics of the non-human world and the symbolic specificity of human semiotics. The need to maintain an ecological attunement between the human symbolic universe and the signical communicative one of the natural cosmos can be considered as a severe warning coming out from the contemporary pandemic. The necessary and adaptive attunement between these two semiotic levels constitutes a third dimension between the Human Semiology inspired to Harris' integrational semiology (see [38]) and the Global Semiotic rooted in Sebeok's signical cosmology of the non-natural world (see [39]. The need for a symbolic/semiotic attunement, as such paralleling a holistic and relational approach to the ecology of the human/nature divide, is amazingly and dramatically materializing in the upheaval that the proxemics of daily life and personal relationships have undergone because of Covid-19. Its global semiotics changed even the signification of the inter-bodily distance and/or proximity. This is because Cov-Sar-II transformed our bodies into real weapons, the proximity of which might be lethal for anybody who is close, dangerously too close, to one of them. The final outcome of such metamorphosis of the inter-corporeal syntax is a radical transformation in the anthropology of space and, thereby, of freedom. Consequentially all the behavioral patterns embodying the projection of freedom-considered in its various declinations-till yesterday, abruptly changed their meaning and axiological signification. Hugs, kisses, handshakes, verbal close communication, etc. equal, now, potential attempts on others' life. For this reason the blatant claims resounded in the name of freedom against the health measures and the social distancing resulting from the lockdown appear semiotically and cognitively off rhythm even before they can be can be considered more or less provided with some foundation of sort. If declined according to their 'past materiality and/ or empirical scope', freedom of movement, association, religion, communication, etc. would be equivalent to a general freedom to kill or, in any case, hurt other people. It is, therefore, the anthropological grammar of spaces and the related proxemics that are to be re-thought before anyone can reasonably, and with an acceptable knowledge of facts, claim for any kind of freedom involving the horizontal and bodily relationships with others. In other words, human symbolic and personal universe and the natural semiotic communicative cosmos are to be considered as parts of only one polyphonic 'musical score.' No voice, in this dynamic processive fresco, can rest on its stillness, avoiding the rhythmical inter-penetration with others. Losing the semiotic synchrony, the ability to co-translate the simultaneity of Otherness, could be catastrophic. For some interesting cues in this vein, see the recent essay collection edited by [16].
} 
system-which assumes itself to be able to survive its othering semantic-spatial ignorance is inherently exposed to the risk of collapse and destined to retrospectively show itself as a surreal expression of an unrealistic cognitive and pragmatic absolutism.

Moreover the simultaneity inherent in the planetary distribution of Covid-19 converted the initial mocking and discriminatory attitude of British people towards Italian immigrants and their healthcare conduct into a form of denial and time marginalization. $^{24}$ The UK Government and society seemed to be determined to deny such simultaneity and with it the semio-spatial continuum of pandemic. In the adoption of this stance, in some sense, British people displaced Italians in a time, as well as in a space, other than their own. The time distinction and the cultural-semantic diffraction were, however, two sides of the same coin, just like it was for the binomial space/meaning. In this regard, however, it is to be observed that categorical borders draw and differentiate both spaces and times. Symmetrically, the later English-Italian homologation of the Covid-19's meaning, implications and the related 'abnormal' health measures mirrored-and, in some sense, reconstructed - the simultaneity and spatial continuum actually coextensive with the global semiotics of the epidemical phenomenon. Furthermore it is to be strongly emphasized that under the lens of law both simultaneity and spatial continuity of epidemic assume-as shown above-a potentially retroactive meaning. An immediate implication of such retroactivity is that simultaneity and continuity, taken together, constitute the foil against which the wrongness of the UK Government's initial assumptions and policy came to the fore also with respect to the evaluative spectrum comprising the legal principles of the UK national legal system, as well as human rights. Nevertheless, there is nothing odd in that. In this respect, it is to be underscored that all meaning creations give shape to dialectical synthesis among manifold potential semantic oppositions and/or tensions, and engender as a result a kind of time/space homogeneous plexus, or block.

To briefly illustrate the process of meaning generation it is possible to take as an explanatory metaphor the experience of reading a sentence. Consider, for this purpose, the following phrase by visualizing, as each term is read, a correspondent image: 'the tree hit by lightning lies charred on the ground.' If the reader will have made a genuine effort to visualize a series of consequent images, s/he will be able to answer the answer that next question. What has the last image in common with the first one? In all likelihood, the answer will be-very little. And yet, in the absence of the first image, the last part of the sentence — charred on the ground-would have no signification, nor could elicit in the mind of an average individual a determined or recognizable form.

While reading, the readers' mind, almost as a rubber band, moves back and forth, so that each previous image is continually remolded and re-signified, also by virtue of an endless implicit semiotic apparatus. The final image includes, at the same time, 'very little and very much' of the image visualized at first. This apparently

\footnotetext{
${ }^{24}$ In some sense this recalls the allochrony observed and theorized in the history of colonization and, precisely, the hermeneutic attitude of colonizers toward the natives of the New World, by [18].
} 
paradoxical combination is the synthesis that shapes and encapsulates the significance of the whole sentence. The meaning will not dwell in its entirety at the beginning, or at the end of the phrase. Conversely, the time to read/interpret the sentence and the sequence of spatialized-even if symbolic - figurations will be unified in the final signification. It will be coextensive with a kind of condensed time, almost still, and a unified space continuum. The portion of eternity-as it were-is thickened in the meaning and the semantic saturation of the corresponding space: but it will be nothing but the dialectic/metaphorical synthesis of all the sequence of times and spaces coextensive with each visualization generated during the reading. In short, the final signification will be the epitome of the dynamic relationship between the plurality of the previous times and spaces.

In order to give some concreteness to the above example, consider the UK situation now (April 24, 2020). With respect to the outbreak, it is embedded in a space-time planetary synthesis, which is attuned-even pragmatically-with the space-time rhythm of Covid-19's spreading, namely its global semiotics. As for the law, in turn, what makes possible such semantic and experiential metamorphoses-think, for example, of the claims for damages by the Italian mothers had they lost custody of their children to the Social Service, or Dr. Jessen's belated apologies $^{25}$ - are precisely the values/ends of British culture, some of which are included in UK legal system and placed at its hierarchical apex. Such values/ends are, even if in many cases only implicitly, part and parcel of the legal statements and their meanings. This is because in law 'is' always means 'ought to be,' and the way something 'is' must correspond to the way in which it 'ought to be' and 'is good.' In other words, 'being' and its 'modes' (to be interpreted somehow echoing Spinoza) are both subjected to an axiological validation. Such underlying and immanent assessment impinges on the semantic spectrum of factual/empirical categorizations included in legal statements. It occurs because the reference to values compels the interpreter to take the empirical categories included in legal statements as means in view of those values/ends. For this reason, the categorical borders and the semantic spectrum of empirical categories change as the axiological and teleological validation/attunement of the phrastic (descriptive) parts of legal rules tend to remold the checklist of what is to be considered 'inside' or 'outside' each category. In other words, the content of such empirical categories is remolded in order to better fit them to function as means for the values/ends legitimizing the overall legal system. This process of semantic adaptation is further incremented by the trans-categoriality of the axiological/teleological categorizations with respect to the empirical ones. It relies upon the common phenomenon for which some elements included in different empirical categories can prove to be functional as means towards the achievement of the same value/end. Such an occurrence, when is noticed and shows its teleological salience, often urges the

\footnotetext{
25 https://www.euroweeklynews.com/2020/03/25/dr-christian-jessen-apologies-to-italians-for-long-siest a-comment/Of course, Jessen is only an example, a kind of communicative protrusion, of a widespread feeling among UK people. Taking in account his statements is interesting just because they can be considered as the tip of a sociological/communicative iceberg.
} 
interpreters to blur and merge the semantic borders of the empirical categories included in the legal rules and/or statements. In all the legal systems providing a judicial review of legislation, for example, the result of such process of re-semanticization takes the following linguistic form: "the legal rule at stake is, or would be, in contrast with constitutional principles insofar as it does not include/provide for... something', or vice versa. Such categorical remolding, however, does not always result in a sentence stating the unconstitutionality of a legal rule. In many cases, it comes as an interpretation in conformity with constitutional principles (in German language, the so-called Verfassungskonforme Auslegung). To put it in more in general terms, the just mentioned trans-categorical continuity can make it so that some categorical checklists will have to be enlarged, and others restricted by reason of the categories' functionality to one value/end or another, as resulting from their reciprocal balancing. As noted above, of course, this value-driven categorical remolding will be the more incisive, the further the interpreter will be able to open the semiotic networks underlying the empirical categorizations and their morphological checklists. Conversely, when this semiotic open-mindedness does not take place, the morphological features can fall prey to an instrumental use, as such cognitively blind if not even surreptitious, aimed at excluding from categorical borders and the related legal effects what could be axiologically and teleologically considered worthy of inclusion, and vice versa.

In both the examples, the tree hit by lightning and the mask/veil pair, as well as that concerning the Italian mothers' refusal to send their children to school during the pandemic, the cognitive values relativize and dissolve the previous distinctions, and trigger, in this way, the generation of a semantic field, as well as a time and a space one, semantically and experientially unified and continuous. I would like to suggest that there is an important lesson to be taken from this occurrence as concerns the geo-legal scope of the values/ends placed at the apex of each legal system. When legal values/ends are actuated by relying on the semiotic networks beneath the morphological appearances of the phenomena to be qualified by the law, they can function as means of cultural externalization and hetero-integration of the national socio-legal systems. At the same time, this approach can foster their function as interfaces for the intercultural inclusion and the generation of inter-spaces of experience. All in all, from the perspective of Italian migrants the change of direction decided by the UK Government in accordance with Italian public health measures, at least with regard to Covid-19 and the lockdown, equals a path of semantic/spatial translation/transaction. As such it engenders a third intercultural space, a kind of metaphorical dome including both the semiotic/pragmatic geographies of both Italian migrants and UK autochthonous people.

Sadly, the above inter-space/third space has come out of a belated hermeneutical 'reshuffle.' But it is to be interpreted as both the defective understanding of the 'real' space coordinates in which all the contemporary human people live (... inter alia, the same of Covid-19) and a pervasive unwillingness to carry out an informed and responsible intercultural translation/transaction as a hermeneutic general standard.

In any case, my hope is that Covid-19's lesson, though tough it has been, can pave the way for a kind of legal/cultural pluralism based on values rather than a 
formal inter-legality, or a rule-based multiculturalism. But the scope of this essay does not allow me to address this topic in further detail. ${ }^{26}$

\section{In the End: Transparent Masks/Veils and Semantic/Material Metamorphosis}

In some respects, the veil issue recalls the face of the asymptomatic individuals with Covid-19. Apparently healthy, their faces hide the (potentially) lethal thread to the others that their bodies, their breath and each act of communication through their mouth and noise pose. Maybe, only a visible, and yet veiled, face could help solve... in one fell swoop, both the Islamic veil/'living together' and the contamination problems. I understand that put like this, it could sound like another of the many paradoxes disseminated along this essay; perhaps, a total absurdity. And yet...

A cue to transcend the paradox could spring up from another extreme situation, or more precisely outside what is usually considered as the human biological and anthropological 'normality.' I refer to the condition of deaf-mutism and the sanitary masks that have been specifically designed to make deaf-mute people's faces veiled, and thereby protected against the Covid-19 contamination, and yet visible. These special masks have been invented in order to allow deaf-mutes to show their facial features so that other people can see and read their lips. ${ }^{27}$

Masks with a transparent central section have been deliberately used to make the human face veiled/masked, and yet visible. Such a solution, after all, could be useful not only for deaf-mute people, but could help combine the health care exigencies and the ECtHR's 'living in common' standards: that is to say the reciprocal recognition through the visibility of the human face, as requested by French law.

A further question is whether covering the face without entirely preventing its visibility —although reduced—can match the semiotic web underlying the Islamic veil beyond the traditional style of dressing. Such an issue cannot be dealt with if not through a worldwide and, simultaneously, locally situated process of multilateral negotiation with the religious representatives, in turn accompanied by serious ethnographic fieldwork. Something similar, for example, took place with regard to the Sikh kirpan. ${ }^{28}$ In the event that the outcome of such a translational and transactional activity were positive, a transparent, or semitransparent, veil would embody a real metaphorical metamorphosis. Through that kind of veil, matter and meaning,

\footnotetext{
${ }^{26}$ For a wider and more accurate analysis of the values-based intercultural legal pluralism I must refer to other writings: see, for example, [41-43].

27 See, for example, https://cbs12.com/news/nation-world/college-student-makes-masks-for-the-deafand-hard-of-hearing, or https://www.kktv.com/content/news/Kentucky-college-student-makes-coronaviru s-masks-for-deaf-community-569331621.html. Some specific adjustments should be required as for the ASL sign for Islamic women wearing the niqab, or the burqa. For deaf-mute Islamic women who wear the niqab or the burqa, there is a clear problem, also because the ASL includes the leap-reading. I think that, when considered, deaf-mute women's condition could be a source of concern also from an Islamic doctrinal viewpoint.

28 As for the kirpan considered from an intercultural perspective I refer to [45].
} 
empirical transformation (transparent plastic instead of opaque fabric) and intercategorical transactions, would comprise a form of translation/transaction capable of putting together and merging different cultural habits and exigencies. It would be, moreover, a genuine metaphor: namely neither politically 'unbalanced', nor the result of a instrumental translation completely blind to the semiotic clouds lying under the morphological appearances shaped from one only cultural, and thereby inevitably ethnocentric, perspective.

The transparent or semitransparent mask, if accepted from both Western and Islamic cultures, would be the icon of a kind of attitude to engender balanced and symmetrical metaphors in interpreting cultural worlds, their respective objects, behavioral habits, and translating their meanings: which, as such, is in keeping with the universal human propensity to produce culture. Moreover, if compared with an eventual intercultural acceptance of a transparent mask/veil, the discriminatory and anti-Enlightenment stigmatization of the traditional Islamic veil for its (also) religious signification would gain 'retrospective clarity.'

In any case, today (April 24, 2020), all the Western countries and their people - to be sure - are about to hear their squares and streets echoing with the vibrant imperative: 'Don't uncover that face!' Like it or not, Western people of any faithparticularly in France and Belgium-will have to come to terms with the cultural inconsistency of this 'fact' as well as, more in general, any identitarian and othering policy and/or psychosocial attitude.

Will something change? Only time will tell, but certainly not without a general commitment to carry out intercultural translations unveiling the semiotic clouds of invisibility lying behind any (not only material) mask or veil.

\section{References}

1. Almila, Anna-Mari, and David Inglis (eds.). 2018. The Routledge International Handbook to Veils and Veiling Practices. Abingdon, Oxon, New York: Routledge.

2. Asad, Talal. 1993. Genealogies of Religion: Discipline and Reasons of Power in Christianity and Islam. Baltimore: Johns Hopkins University Press.

3. Asad, Talal. 2003. Formation of the Secular: Christianity, Islam, Modernity. Stanford: Stanford University Press.

4. Blumenberg, Hans. 1985. The Legitimacy of Modern Age. Cambridge: The MIT Press.

5. Blumenberg, Hans. 2007. Theorie der Unbegrifflickkeit. Frankfurt a. M: Suhrkamp.

6. Brems, Eva (ed.). 2014. The Experiences of Face Veil Bearers in Europe and the Law. Cambridge: CUP.

7. Brett, Annable. 2019. The Subject of Sovereignty: Law, Politics and Moral Reasoning in Hugo Grotius. Modern Intellectual History. https://doi.org/10.1017/S1479244319000040.

8. Casanova, Jose. 2011. The Secular, Secularizations, Secularisms. In Rethinking Secularism, ed. Craig Calhoun, Mark Juergensmeyer, and Jonathan VanAntwerpen, 54-74. Oxford, New York: Oxford University Press.

9. Cox, Neville. 2019. Behind the Veil. A Critical Analysis of European Veiling Laws. Cheltenham, Northampton (MA): Edward Elgar Publishing.

10. Dewey, John. 1916. Democracy and Education. New York: The McMillan Company.

11. Di Paolo, Ezequiel A. 2020. Enactive Becoming. Phenomenology and Cognitive Science. https:// doi.org/10.1007/s11097-019-09654-1.

12. Di Paolo, Ezequiel A., Elena C. Cuffari, and Hanne De Jaegher. 2018. Linguistic Bodies. The Continuity between Life and Language. Cambridge, MA, London: The MIT Press. 
13. Dressler, Markus, and Arvind-Pal S. Mandair. 2011. Modernity, Religion Making, and the Postsecular. In Secularism and Religion-Making, ed. Id, 3-36. Oxford: Oxford University Press.

14. Dwyer, Claire. 1999. Veiled Meanings: Young British Muslim Women and the Negotiation of Differences. Gender, Place \& Culture: A Journal of Feminist Geography 6 (1): 5-26. https://doi. org/10.1080/09663699925123.

15. Dwyer, Claire. 2008. The Geographies of Veiling: Muslim Women in Britain. Geography 93 (3): $140-147$.

16. Ellis, Mureen (ed.). 2020. Critical Global Semiotics: Understanding Sustainable Transformational Citizenship. Abingdon, Oxon, New York: Routledge.

17. Erts, Stefanie. 2016. Hugo Grotius's Hermeneutics of Natural and Divine Law. Grotiana 37 (1): 61-94. https://doi.org/10.1163/18760759-03700004.

18. Fabian, Johannes. 1983. Time and the Other: How Anthropology Makes its Object. New York, Chichester: Columbia University Press.

19. Galadari, Abdulla. 2012. Behind the Veil: Inner Meanings of Women's Islamic Dress Code. The Journal of Interdisciplinary Social Sciences 6 (11): 115-125.

20. Geddert, Jeremy S. 2017. Hugo Grotius and the Modern Theology of Freedom: Transcending Natural Rights. Abingdon, Oxon, New York: Routledge.

21. Gökariksel, Banu, and Katharyne Mitchell. 2005. Veiling, Secularism, and the Neoliberal Subject: National Narratives and Supranational Desires in Turkey and France. Global Networks 5 (2): 147165. https://doi.org/10.1111/j.1471-0374.2005.00112.x.

22. Gordley, James. 1993. The Philosophical Origins of Modern Contract Law. Oxford, New York: OUP.

23. Grotius, Hugo 2013. De jure belli ac pacis libri tres in quibus jus naturae et gentium item iuris publici praecipua explicantur. Eds. Feenstra, Robert, Persenaire, Caroline, E. Aalen: Scientia Verlag und Antiquariat.

24. Habermas, Jürgen. 2008. Between Naturalism and Religion: Philosophical Essays. Hoboken, NJ: Wiley.

25. Henare, Amiria, Martin Holbraad, and Sari Wastell. 2007. Thinking through Things: Theorising Artefacts Ethnographically. Abingdon, Oxon New York: Routledge.

26. Horkheimer, Max, and Theodor W. Adorno. 2002. Dialectic of Enlightement. Philosophical Fragments. Stanford (CA): Stanford University Press.

27. Jackson, Michael. 1996. Introduction: Phenomenology, Radical Empiricism, and Anthropological Critique. In Things as They Are: New Directions in Phenomenological Anthropology, ed. Id. Bloomington, Indianapolis: Indiana University Press.

28. Kalantry, Sital, Pradhan Maithili 2017. Veil Ban in the European Court of Human Rights. American Society of International Law. At https:/www.asil.org/insights/volume/21/issue/15/veil-bans-europ ean-court-human-rights. Last Accessed 20 April 2020.

29. Koskenniemi, Martti. 2019. Imagining the Rule of Law: Rereading the Grotian 'Tradition'. European Journal of International Law 30 (1): 17-52. https://doi.org/10.1093/ejil/chz017.

30. Mahmood, Saba. 2010. Can Secularism be Otherwise? In Varieties of Secularism in a Secular Age, ed. Michael Warner, Jonathan VanAntwerpen, and Craig Calhoun, 282-299. Cambridge, MA: Harvard University Press.

31. Mahmood, Saba. 2016. Religious Difference in a Secular Age: A Minority Report. Princeton, Oxxford: Princeton University Press.

32. Mandair, Arving-Pal S. 2009. Religion and the Specter of the West: Sikhism, India, Postcoloniality, and the Politics of Translation. New York: Columbia University Press.

33. May, Larry, and Emily McGill (eds.). 2016. Grotius and the Law. Abingdon, Oxon, New York: Routledge.

34. Mendieta, Eduardo. 2014. The Silence of the Sirens: Rereading the Dialectic of Enlightenment with Kafka and Borges. The Journal of Speculative Philosophy 28 (3): 401-410. (Special issue with the society for phenomenology and existential philosophy).

35. Modood, Tariq. 2019. Essays on Secularism and Multiculturalism. Lanham: ECPR Press/Rowman \& Littlefield International.

36. Mookherjee, Monica. 2019. Womens' Rights as Multicultural Claims: Reconfiguring Gender and Diversity in Political Philosophy. Edinburgh: Edinburgh University Press.

37. Nagel, Caroline, and Lynn A. Staehely. 2008. Integration and the Politics of Visibilities and Invisibilities in Britain. In New Geographes or Race and Racism, ed. Dwyer, Claire, Bressey, 83-94. Aldershot, Burlington (VT): Ashgate. 
38. Pablé, Adrian. 2016. Global Semiotics vs. Human Semiology: Understanding communication in the 21st century. Chinese Semiotic Studies 12 (1): 25-43. https://doi.org/10.1515/css-2016-0004.

39. Petrilli, Susan. 2015. Language, Communication, and Speech: Human Signs in Global Semiosis. Semiotica 204: 173-237.

40. Phillippopoulos-Mihalopoulos, Andreas 2020. Covid: The Ethical Disease. Critical Legal Thinking. https://criticallegalthinking.com/2020/03/13/covid-the-ethical-disease/.

41. Ricca, Mario. 2008. Culture interdette. Modernità, migrazioni, diritto interculturale. Torino: Bollati Boringhieri.

42. Ricca, Mario 2014. Intercultural Law, Interdisciplinary Outlines: Lawyering and Anthropological Expertise in Migration Cases Before the Courts. In E/C Rivista Telematica dell "Associazione Italiana di Studi Semiotici: 1-53. Available at http://www.ec-aiss.it/index_d.php?recordID=709.

43. Ricca, Mario 2016. Errant Law: Spaces and Subjects: 1-54. https://ssrn.com/abstract=2802528. http://dx.doi.org/10.2139/ssrn.2802528. Accessed 30 June 2016.

44. Ricca, Mario. 2016. Polifemo. La cecità dello straniero. Palermo: Torri del Vento.

45. Ricca, Mario. 2018. Ignorantia Facti Excusat: Legal Liability and the Intercultural Significance of Greimas' "Contrat de Véridition". International Journal for the Semiotics of Law 31: 101-126. https ://doi.org/10.1007/s11196-017-9529-6.

46. Schmitt, Carl 2005 (or 1922). Political Theology: Four Chapters on the Concept of Sovereignty. Chicago: The University of Chicago Press.

47. Sebeok, Thomas A. 2001. Global Semiotics. Bloomington, Indiana: Indiana University Press.

48. Taylor, Charles. 2007. A Secular Age. Cambridge: Harvard University Press.

49. Taylor, Charles. 2011. Why We Need a Radical Redefinition of Secularism. In The Power of Religion in the Public Sphere, ed. Eduardo Mendieta and Jonathan Antwerpen, 34-59. New York: Columbia University Press.

50. Tierney, Brian. 2001. The Idea of Natural Rights: Studies of Natural Rights, Natural Law and Church Law 1150-1625. Grand Rapids (Michigan), Cambridge: Eerdmans Publishing.

Publisher's Note Springer Nature remains neutral with regard to jurisdictional claims in published maps and institutional affiliations.

\section{Affiliations}

\section{Mario Ricca $^{1}$}

Mario Ricca

mario.ricca@icloud.com

1 University of Parma, Parma, Italy 